\title{
Commentary: Using ex vivo modeling to validate technical innovations in cardiac surgery
}

\author{
R. Scott McClure, MD, and Paul W. M. Fedak, MD, PhD
}

\author{
From the Section of Cardiac Surgery, Department of Cardiac Sciences, Cumming School of Medicine, University \\ of Calgary, Libin Cardiovascular Institute of Alberta, Calgary, Alberta, Canada. \\ Disclosures: Authors have nothing to disclose with regard to commercial support. \\ Received for publication Feb 4, 2019; accepted for publication Feb 4, 2019; available ahead of print March 8, \\ 2019. \\ Address for reprints: Paul W. M. Fedak, MD, PhD, C880, 1403 29th St NW, Calgary, Alberta T2N 2T9, Canada \\ (E-mail: paul.fedak@gmail.com). \\ J Thorac Cardiovasc Surg 2019;158:404-5 \\ $0022-5223 / \$ 36.00$ \\ Copyright (c) 2019 by The American Association for Thoracic Surgery \\ https://doi.org/10.1016/j.jtcvs.2019.02.010
}

Optimal function of the human aortic root complex relies on a coordinated interaction of its dynamic parts in a seemingly infinite repetition. Surgeons have embraced the concept that form follows function. We may not all agree on which shape of the aortic root best supports optimal function of the aortic valve. Many of our insights into aortic root structure and function were obtained by static state descriptive analyses derived from human autopsy studies and from limited in vivo large animal models. The biophysical properties inherent to proper aortic root function are inadequately observed and predicted by such investigations. Assessing the interplay between the aortic sinus shape and the resulting effects on valve function through the in vivo acquisition of clinically relevant biomechanical properties has proved to be a formidable challenge. In their article in this edition of the Journal, Paulsen and colleagues ${ }^{1}$ have aimed to circumvent this obstacle by using a sophisticated and novel ex vivo model of aortic valve-sparing root reconstruction.

Through a collaborative effort between surgeons and biomedical mechanical engineers, Paulsen and colleagues ${ }^{1}$ designed an ex vivo heart simulator outfitted specifically to assess the hemodynamic and biomechanical properties of the aortic root during valve-sparing root replacement procedures. The advantage of this model is the tight control of variables to isolate the influence of subtle structural changes on optimal valve function. Despite our often useful anecdotal experiences as surgeons, we cannot achieve this level of objective evidence by studying our patients alone. In porcine hearts controlled for annular diameter, a single surgeon performed 6 "classic" David I valvesparing root replacements with a straight polyester graft and 6 valve-sparing root replacements with a Valsalva graft. Hemodynamics proved similar between the 2 repair techniques, with a trend seen toward higher transvalvular gradients and a smaller effective orifice area with the

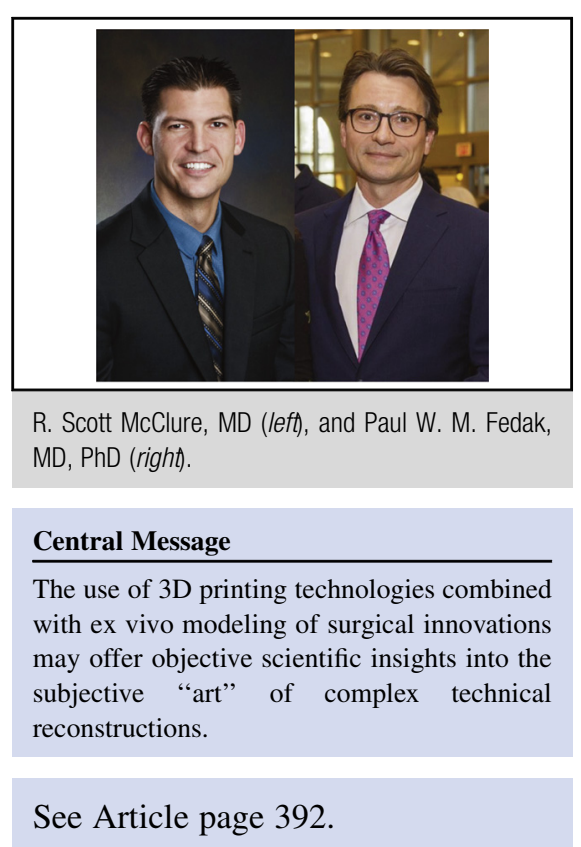

straight graft technique. Use of the Valsalva graft resulted in significantly higher leakage and volumes, resulting in a higher regurgitant fraction relative to straight grafts. The Valsalva grafts also had higher peak radial intercommissural separation, reduced coaptation height, and higher leaflet forces relative to the straight graft repairs. From these findings taken together, Paulsen and colleagues ${ }^{1}$ suggest that the hypothesized benefits of neosinus creation may be eclipsed by a negative effect imposed by commissural distortion. This is a provocative message, given that such benefits are supported by in vivo studies that have used 4-dimensional flow magnetic resonance imaging ${ }^{2}$ of flow dynamics.

Producing an ex vivo model of the complex human aortic root is an ambitious endeavor. The clinical relevance and generalizability of any ex vivo model will always be questioned. Notwithstanding such standard and expected constructive criticisms, this pioneering investigative effort that uses 3-dimensionally printed simulation shows the potential to be highly informative in shaping surgical innovations. These preliminary studies provide a foundation for further ex vivo models to advance our understanding of the key factors that may influence long-term durability of 
valve-sparing aortic root repairs. Although patient selection and surgeon expertise will always be at the forefront of long-term outcomes in valve-sparing procedures, these unique insights into optimal graft selection may add some science to the technical art of valve-sparing root reconstructions.

\section{References}

1. Paulsen MJ, Kasinpila P, Imbrie-Moore AM, Wang H, Hironaka CE, Koyano TK, et al. Modeling conduit choice for valve-sparing aortic root replacement on biomechanics with a 3-dimensional-printed heart simulator. J Thorac Cardiovasc Surg. 2019;158:392-403.

2. Gaudino M, Piatti F, Lau C, Sturla F, Weinsaft JW, Weltert L, et al. Aortic flow after valve sparing root replacement with or without neosinuses reconstruction. J Thorac Cardiovasc Surg. 2019;157:455-65. 